\title{
ANÁLISE DO SANEAMENTO BÁSICO DA COMUNIDADE DO CAMPESTRE NO MUNICÍPIO DE SEABRA/BA ATRAVÉS DE UM DIAGNÓSTICO SOCIOAMBIENTAL PARTICIPATIVO
}

Erica Teles de Souza - erikateles29@gmail.com

Estudante no curso Técnico em Meio Ambiente no Instituto Federal da Bahia

Esther Moura Jorge de Oliveira - EMJoliveira@otlook.com

Estudante no curso Técnico em Meio Ambiente no Instituto Federal da Bahia

Erica Chaves de Souza - chaveserica02@gmail

Estudante no curso Técnico em Meio Ambiente no Instituto Federal da Bahia

Francisco Ramon Alves do Nascimento - ramonacademico@gmail.com

Docente no Instituto Federal da Bahia

Lucio Aderito dos Anjos Veimrober Junior - agrolucio10@ gmail.com

Docente no Instituto Federal da Bahia 


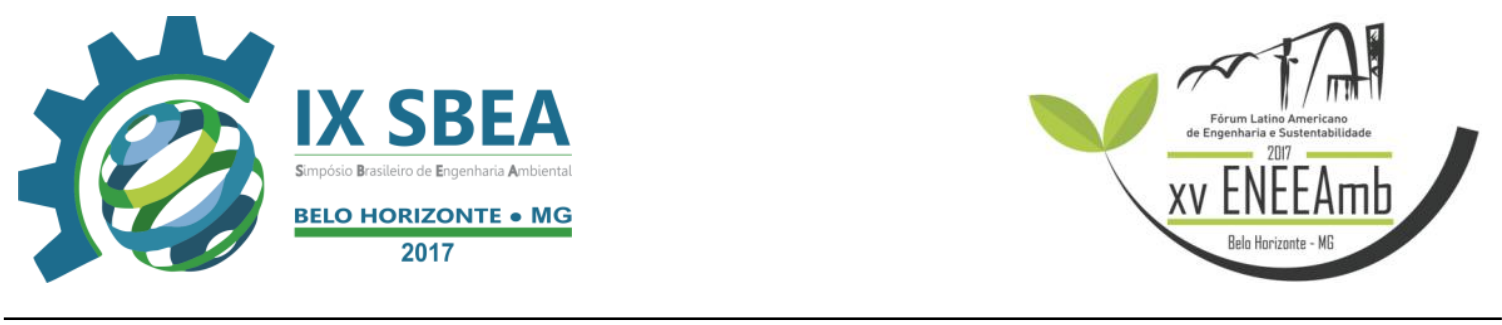

\section{RESUMO}

Esse trabalho apresenta análises do saneamento básico, juntamente com a aplicação do Diagnóstico Socioambiental Participativo (DSP) na comunidade do Campestre antiga sede do município de Seabra, localizado no Territótio da Chapada Diamantina, estado da Bahia. Elaborado pelos discentes do Instituto Federal de Educação, Ciência e Tecnologia da Bahia (IFBA) Câmpus Seabra, foram avaliados os resultados do DSP da comunidade, usando como metodologia aplicação: "Árvores dos Sonhos", Muro das Lamentações" e questionários pessoais a fim de identificar as dificuldades e a ausência de instrumentos do saneamento básico da comunidade. Dessa forma, os resultados da metodologia utilizada indicou que por falta de saneamento adequado, a comunidade é obrigada a adotar medidas, que não são adequadas, como por exemplo, a queima de resíduos sólidos, o consumo de água sem tratamento e lançamentos irregular de efluentes. Deste modo, foram propostas as soluções viáveis e práticas para solucionar os problemas encontrados.

Palavras-chave: Saúde; Qualidade de vida; DSP.

\section{INTRODUÇÃO/OBJETIVO}

De acordo com o art. 225 da Constituição Federal CF/88 (2011, p. 81), o ser humano tem "direito ao meio ambiente ecologicamente equilibrado, bem de uso comum do povo e essencial à sadia qualidade de vida, impondo-se ao Poder Público e à coletividade o dever de defendê-lo e preservá-lo para as presentes e futuras gerações".

O saneamento básico é uma ferramenta que contribui para o desenvolvimento sustentável e assegurar este direito. Segundo Rocha (2009), o saneamento básico tem fundamental importância na preservação dos recursos hídricos e melhoria da saúde pública, já que quando bem planejado ajuda na minimização dos impactos negativos causados ao meio ambiente. O saneamento básico é composto pelos serviços de abastecimento de água potável, manejo das águas pluviais, coleta e tratamento de esgoto e manejo de resíduos sólidos.

No Brasil, o abastecimento de água é o serviço com maior índice de acesso pela população. Sendo os outros serviços prestados de forma precária nas zonas 
urbanas. Essa realidade é mais preocupante quando analisada a questão do saneamento nas zonas rurais.

Segundo o Instituto Brasileiro de Geografia e Estatística, em 2009, aproximadamente $75 \%$ da população rural do país não teve acesso à rede de coleta ou ao tratamento de esgoto (IBGE, 2011 apud COSTA \& GUILHOTO, 2014). As regiões rurais do Brasil são distintas no acesso aos serviços, por exemplo, a região sudeste tem $66 \%$ da população rural sem acesso à rede coletora de esgoto, enquanto na região Nordeste $84 \%$ do esgoto produzido não é coletado (IBGE, 2011 apud COSTA \& GUILHOTO, 2014) A falta de saneamento adequado afeta no desenvolvimento de comunidades rurais. A falta de manejo dos resíduos sólidos em zonas rurais é outro fator preocupante.

Assim, faz-se necessário o investimento do Poder Público em saneamento nas zonas rurais como previsto na Lei $\mathrm{n}^{\mathrm{o}} 11.445 / 2007$, que estabelece a Política Nacional de Saneamento Básico.

O diagnóstico da realidade de cada comunidade rural pode proporcionar uma forma mais eficiente dos investimentos no setor de saneamento, isto porque cada comunidade tem suas características próprias.

Portanto, a participação efetiva da comunidade contribui para que o poder público direcione o foco de suas políticas públicas de acordo com a necessidade local. As etapas de formulação e execução de ações e programas governamentais com a participação da comunidade são desenvolvidas com mais eficiência. Isto porque a falta de participação da comunidade é apontada como uma das principais causas do fracasso de políticas, programas e projetos de diferentes tipos (BANDEIRA, 1999).

De acordo com Cerqueira (2004) sem a elaboração de um diagnóstico não se pode identificar as necessidades particulares de cada lugar e os programas oferecidos acabam sendo inadequados, pois não se aplica a realidade de cada local. Assim, soluções mais adequadas de saneamento, para um determinado local podem ser encontradas a partir da efetivação de um Diagnóstico Socioambiental Participativo (DSP). O DSP é considerado uma ferramenta que permite a construção do trabalho de profissionais juntamente com a comunidade, através de levantamentos que permitem que as comunidades compartilhem e considerem suas percepções acerca de suas 


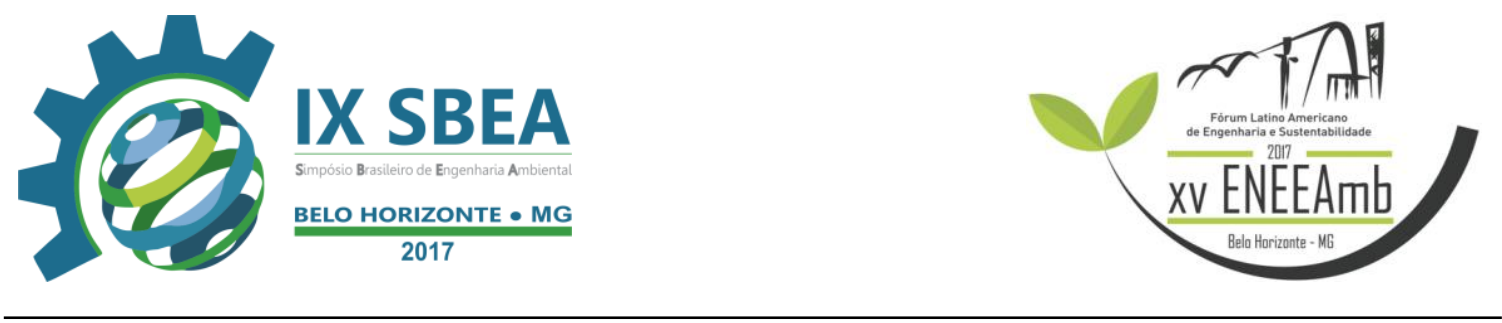

realidades, subsidiando desta maneira a elaboração e proposição de novas ações para mudança da realidade.

O DSP é uma série de análises para detectar as causas e os problemas locais. Cerqueira (2004) afirma que os projetos participativos permitem a comunidade decidir quais mudanças, inovações ou intervenções seriam mais adequadas, e favoráveis para melhorar suas condições no meio em que vive. Dessa forma a comunidade tem papel importante na participação do diagnóstico, pois permite a priorização das soluções dos problemas vivenciados no cotidiano.

Portanto, este trabalho tem por objetivo avaliar o saneamento básico da comunidade do Campestre no município de Seabra/Ba, por meio de um diagnóstico socioambiental participativo.

\section{METODOLOGIA}

Este trabalho foi realizado na comunidade do campestre, que é a antiga sede econômica do município de Seabra, estado da Bahia. O município está localizada no centro geográfico da Bahia, a $458 \mathrm{~km}$ de Salvador. Atualmente, a comunidade tem cerca de 70 famílias e aproximadamente 210 habitantes. A região é caracterizada por um bioma de Caatinga, um clima tropical com estação seca, (Semiárido).

O diagnóstico socioambiental participativo foi realizado por meio da aplicação de questionários nas residências da comunidade do Campestre. O questionário foi baseado em trabalhos acadêmicos e composto por 34 questões, estas divididas em sete categorias de informação, além disso foram aplicadas as metodologias: "Muro das Lamentações" e "Árvores dos Sonhos" que auxiliaram na identificação das necessidades específicas da comunidade. O objetivo foi analisar o perfil do entrevistado, o núcleo familiar e aspectos da comunidade, como abastecimento de água, esgotamento sanitário e coleta e destino dos resíduos sólidos.

\section{RESULTADOS E DISCUSSÃO}

A partir das visitas a comunidade, foi perceptível que os resíduos sólidos produzidos pela comunidade são armazenados de forma inadequada (Figura 01), sendo possível ambiente para proliferação de vetores. Outro aspecto identificado foi o lançamento de esgoto a céu aberto na zona central da comunidade (Figura 02). 

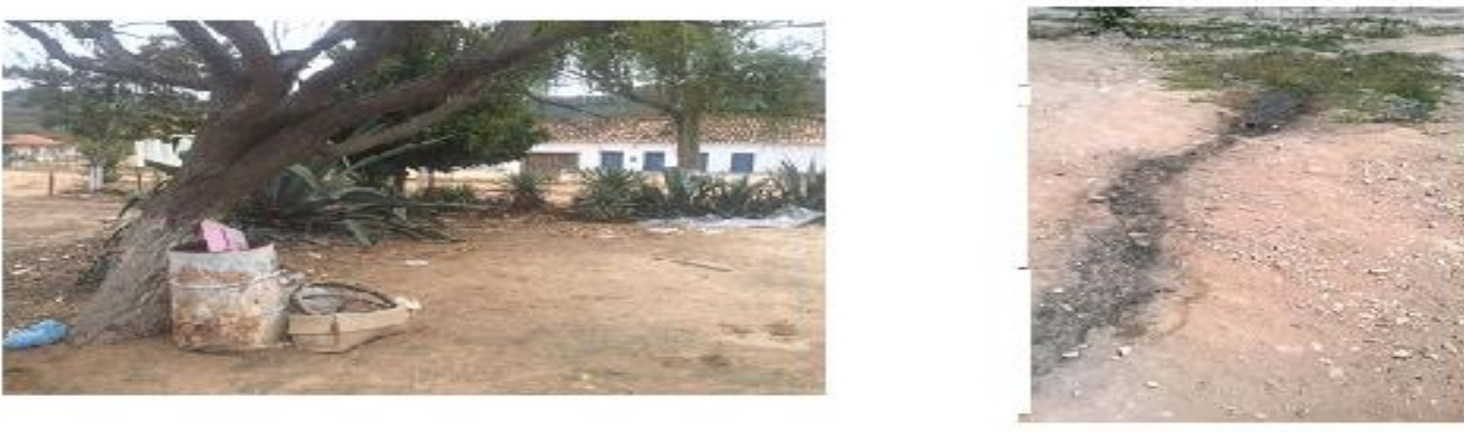

Figura 1 e Figura 2 respectivamente. Foto da comunidade (Fonte: próprios autores, 2017).

Em relação ao questionário, foram entrevistadas 44 pessoas da comunidade do Campestre, sendo a maioria líderes familiares. Em relação às categorias "Perfil do entrevistado" e "Família", quando questionados sobre sua escolaridade, cerca de 57\% afirmaram que possuíam ensino fundamental incompleto. Este fato pode comprometer a aplicação de políticas públicas voltadas para o setor saneamento. As principais fontes de renda da comunidade são agricultura e os benefícios sociais, como pensão ou aposentadoria. Mais da metade das famílias são compostas por 4 (quatro) ou mais pessoas.

Quando questionados se alguém na família apresentou alguma doença ou algum tipo de problema que possa estar relacionado com água, resíduos, esgoto ou água de chuva, cerca de $90 \%$ responderam que não tinham problemas. A percepção quanto à qualidade do ambiente da comunidade foi definida 61,4\% como "Agradável" e 25\% como "Muito Agradável". Quanto à contribuição para a preservação do meio ambiente, cerca de $60 \%$ afirmaram que já contribuiu ou contribuem com ações. Como o não desmatamento.

Sobre a categoria “Água”, 40,9\% disseram que são abastecidos por meio da rede pública e 38,6\% através de poços subterrâneos próprios. Os demais são abastecidos 


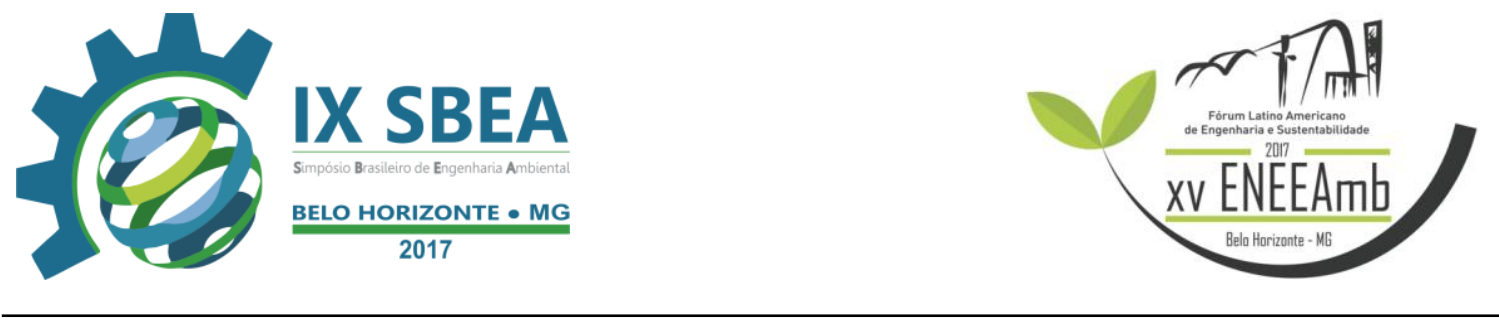

de outra forma, como através de cisternas e captação direta de água do rio próximo à comunidade.

Em relação à frequência do abastecimento de água através da rede pública, 95,5\% responderam que acontecia 2 (duas) vezes por semana. Quanto a problemas com a água abastecida, 56,8\% afirmaram ter problemas. De acordo com a Figura 3, quando questionados sobre a satisfação em relação a qualidade da água, 34\% e 18\% responderam estar "Insatisfeito" e "Pouco Satisfeito", respectivamente. Alguns moradores relataram que água de abastecimento tinha coloração amarelada, o que possivelmente deve ser por causa do teor de ferro, típico da região, ou provavelmente a presença de matéria orgânica acumulada.

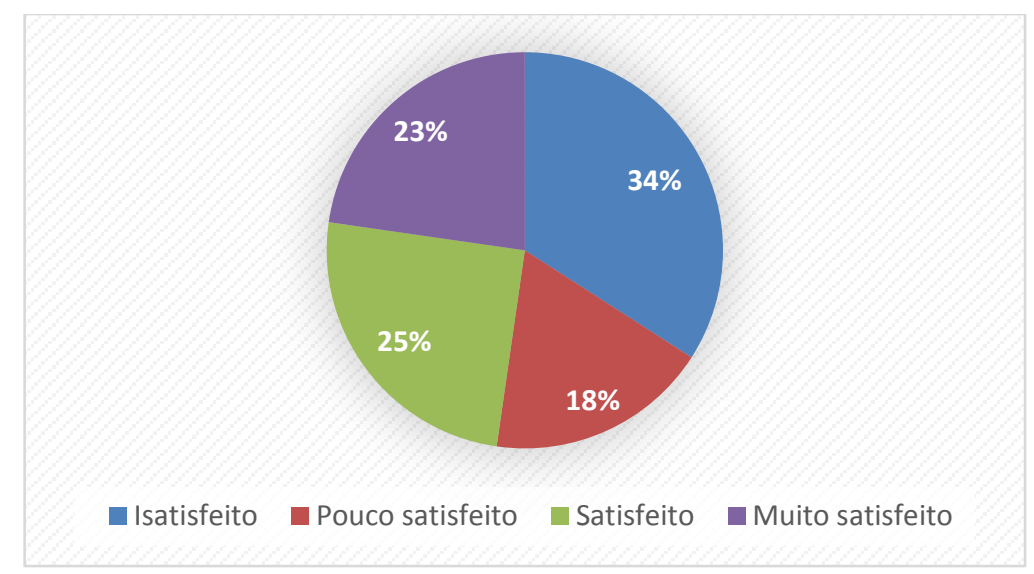

Figura 3. Satisfação dos moradores em relação a qualidade da água.

De acordo com as respostas, $45,5 \%$ responderam que a forma de armazenamento de água da residência era feita através de reservatórios de PVC, 11,4\% através de bombonas (pipas), 4,5\% através de cisternas e 38,6\% através de outras formas. Quanto à existência de tratamento da água para beber, $42 \%$ responderam que faziam filtração e $49 \%$ responderam que não sabiam se ocorria algum tipo de tratamento, de acordo com a Figura 4. No entanto, aproximadamente $72 \%$ afirmaram que utilizam filtro de barro nas residências. 

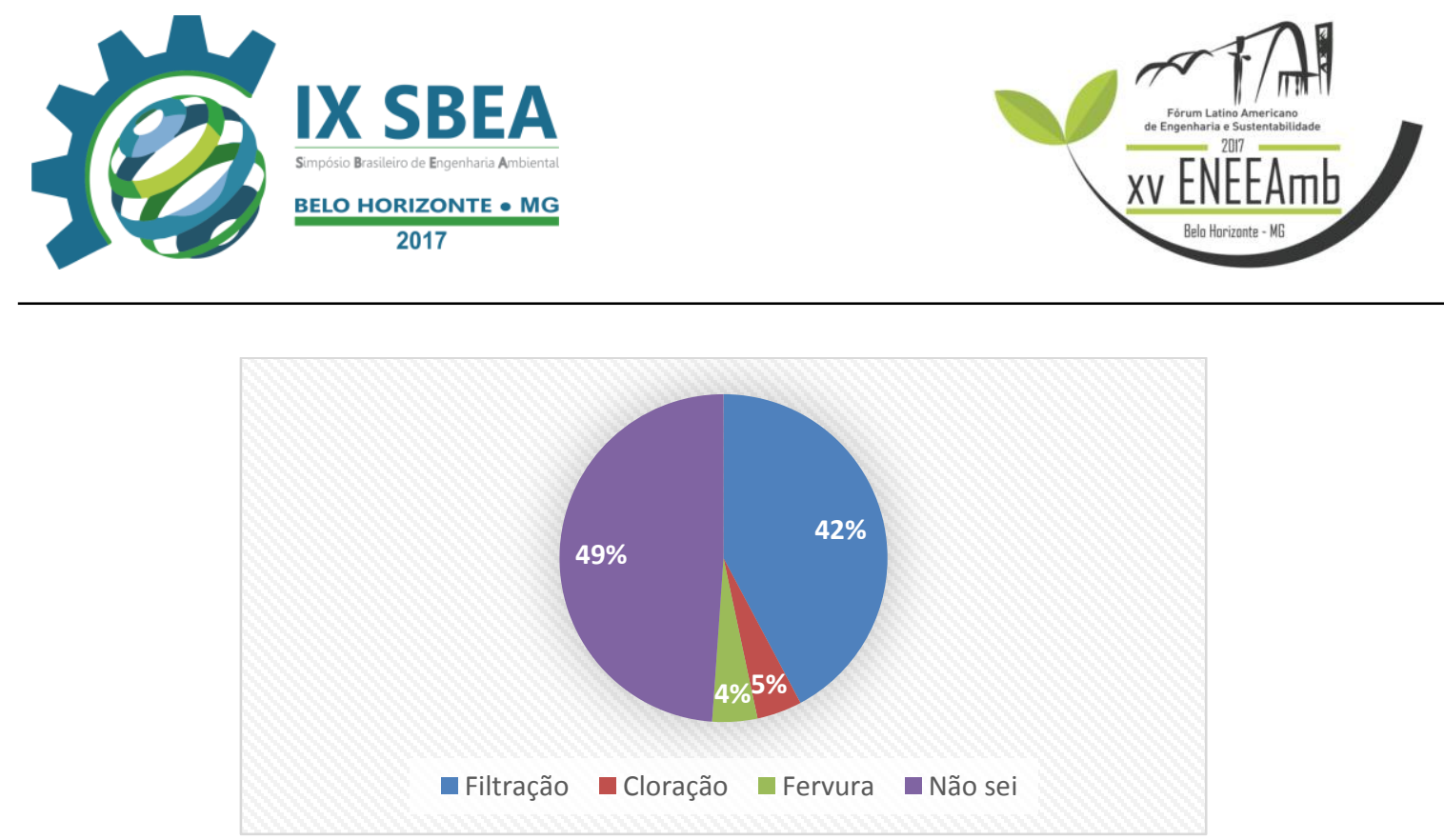

Figura 4. Tipo de tratamento da água para consumo adotado, segundo os moradores.

$\mathrm{Na}$ categoria "Esgoto", 61\% tem como destino do esgoto produzido fossas rudimentares, $14 \%$ lançam no próprio terreno a céu aberto e $11 \%$ lançam na rua (Figura 5). Apesar de $25 \%$ do esgoto produzido ser lançados a céu aberto, 95,5\% dos entrevistados responderam que não sentem odor de esgoto.

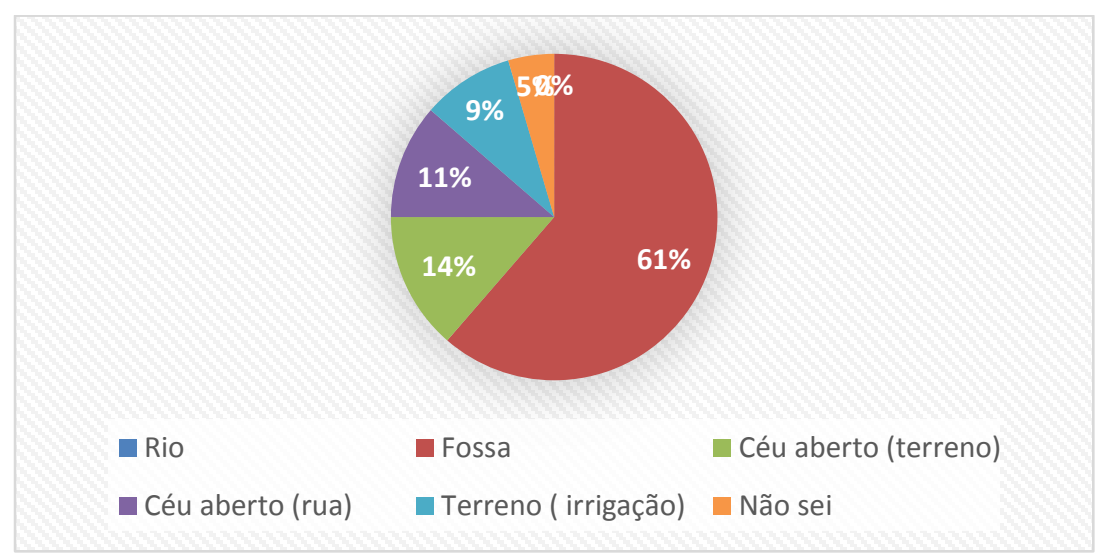

Figura 5. Destino do esgoto produzido nas residências.

Ao responderem a questão "Quantas vezes por semana ocorre a coleta municipal de resíduos (lixo)?”, 68\%, 18\% e 14\% responderam que ocorria apenas 1 vez por semana, mais de 2 vezes por semana e não sabiam, respectivamente. Quanto à satisfação do serviço de coleta de resíduos sólidos, apenas $25 \%$ responderam que estavam "Insatisfeito" ou "Pouco satisfeito", de acordo com a Figura 6. 

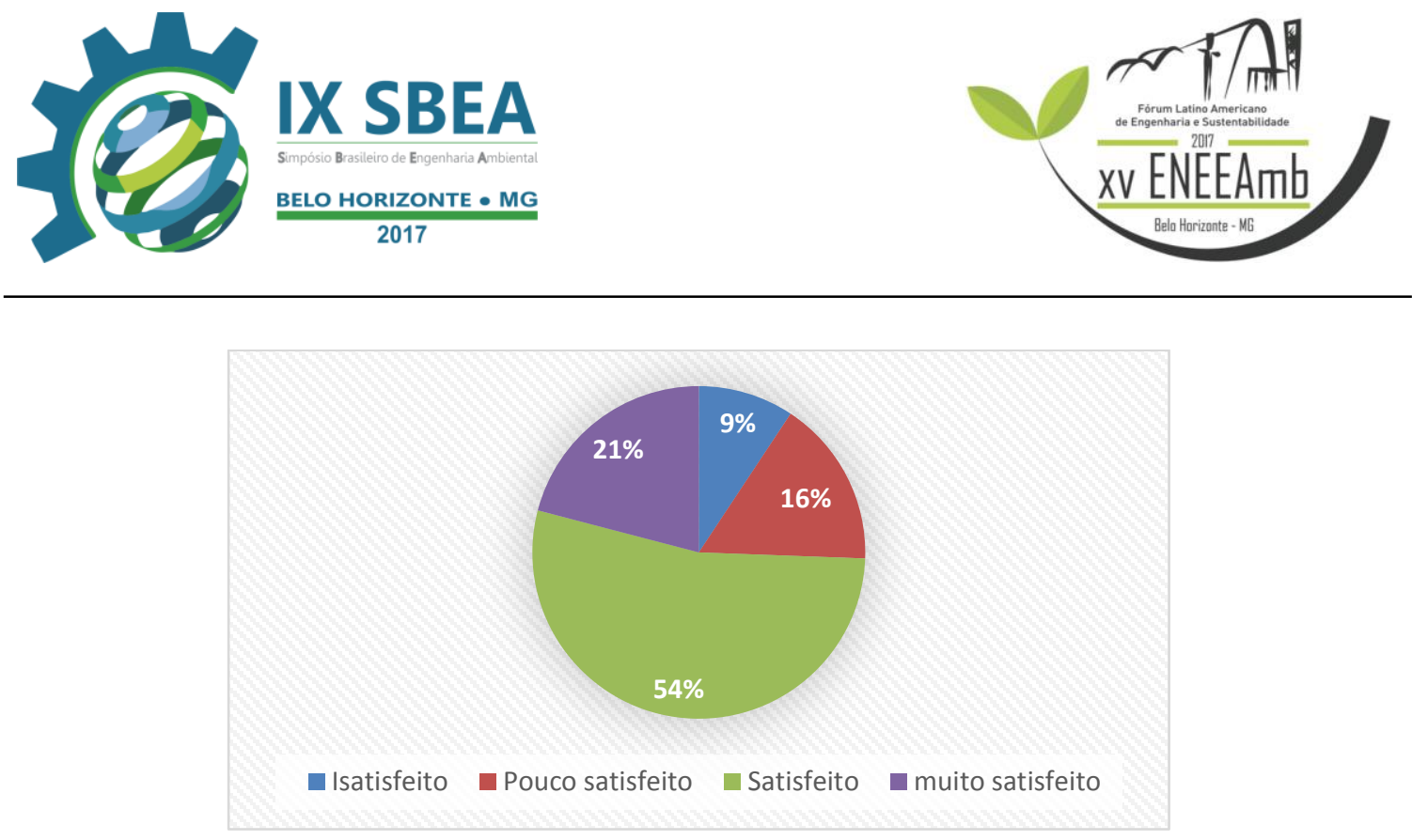

Figura 6. Satisfação em relação a coleta de resíduos na comunidade.

Quanto ao destino dos resíduos sólidos, 59\% afirmaram que não sabiam o destino dos resíduos sólidos. Em relação ao conhecimento das opções de destinação adequada dos resíduos sólidos, como: 1) compostagem, 2) reciclagem e 3) coleta seletiva, $91 \%, 50 \%$ e $75 \%$ responderam não saber o que estes conceitos significavam, respectivamente.

Sobre as questões relacionadas à água de chuva, $88,6 \%$ e $81,8 \%$ dos entrevistados responderam que não ocorria alagamento nos períodos chuvosos nas residências e na rua, respectivamente. Quanto ao armazenamento e utilização de água de chuva, 54,5\% responderam que não realizam.

A população tem a percepção de uma comunidade com uma qualidade ambiental agradável ou muito agradável, no entanto qualidade ambiental pode se referir as características variadas das condições do meio ambiente, expressas em termos de indicadores ou índices relacionados com os padrões de qualidade ambiental (IBAMA, 2016). No entanto, por meio de observações feitas, percebe-se que a comunidade não apresenta qualidade ambiental adequada, devido ao esgoto a céu aberto, falta de espaço de lazer, falta de arborização e falta de pavimentação. Diante do exposto, pode-se analisar que a comunidade não tem a percepção clara dos aspectos da qualidade ambiental.

O saneamento básico, por melhorar as condições ambientais, promove a melhoria da saúde pública e qualidade ambiental, por isso a introdução de saneamento 


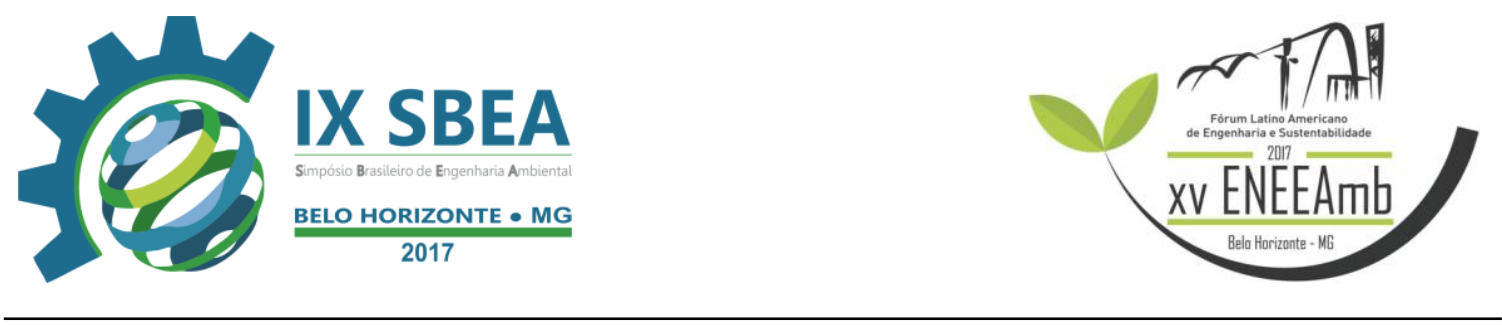

básico é de fundamental importância para as soluções dos problemas identificados na comunidade.

A escassez hídrica na comunidade é evidente, causada por processos antrópicos, tais como a irrigação, o que tem reduzido a vazão do rio Campestre. $\mathrm{O}$ sistema de abastecimento de água, que é feito por meio de um poço artesiano, é operado pela Central de Associações. No entanto, existe resistência da comunidade para o consumo da água ofertada, uma vez que de acordo com a percepção da comunidade, devido a coloração amarelada e ao odor causado pelo uso de produtos químicos no tratamento da água, esta não serve para o consumo dos moradores. Uma das soluções pode ser a melhoria da operação da estação de tratamento de água. É importante ressaltar que não foram realizadas análises da qualidade da água de captação nem da água distribuída.

A água utilizada para beber é retirada de outro poço aberto em uma propriedade privada, onde o proprietário disponibiliza a água para a população. A água, não passa por uma Estação de Tratamento de Água (ETA), no entanto para consumo humano deve-se fazer algum tipo de tratamento. No entanto, foi identificado que $49 \%$ da população não sabem como fazer o tratamento simplificado da água. Cerca de $65 \%$ da população utilizam filtro de barro em suas residências, o que pode minimizar os riscos de contaminação devido ao uso da água sem tratamento.

Outro aspecto que compõe o saneamento básico é o manejo e disposição correta de resíduos sólidos. De acordo com Ribeiro \& Rooke (2010), a disposição e armazenamento inadequados dos resíduos a céu aberto, causam inevitáveis problemas sanitários e ambientais, uma vez que esses locais tornam-se favoráveis para a proliferação de animais que podem tornar-se possíveis transmissores de doenças.

Tendo essa afirmação como base, podemos deduzir que as pessoas da comunidade estão propicia a contraírem doenças, visto que a coleta, da maioria dos moradores é feita uma vez por semana. A disposição final dos resíduos sólidos é o vazadouro da cidade. Durante o período de armazenamento dos resíduos a céu aberto, um possível criadouro de vetores como ratos, moscas, mosquitos e baratas pode ser estabelecido, expondo assim a comunidade a doenças como leptospirose, disenteria, 


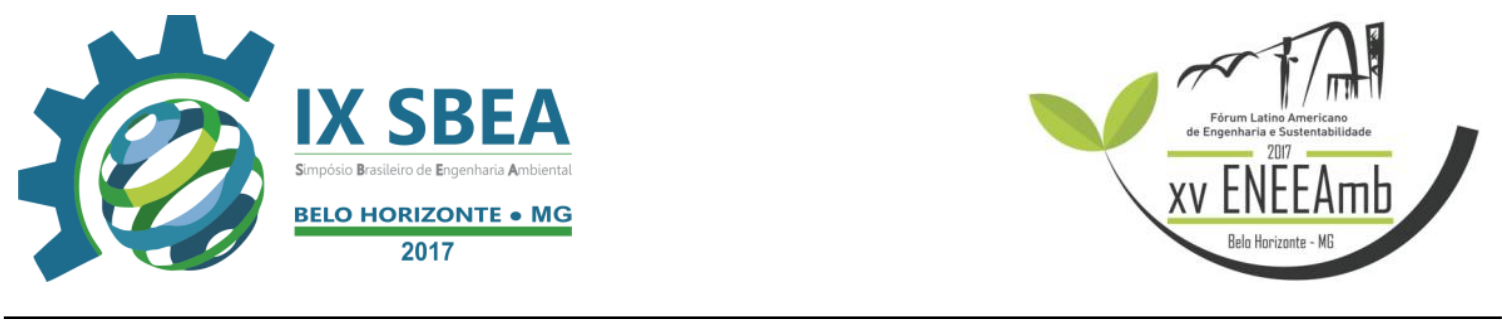

leishmaniose, febre amarela e dengue. Devido ao armazenamento inadequado dos resíduos, alguns moradores preferem queimar seus resíduos, solução que estes encontraram para reduzir o volume de resíduos, no entanto ao realizarem essa prática, podem provocar a poluição do ar.

Dessa forma, é visto como solução, a disponibilização de tambores com tampas, para acondicionarem esses resíduos até o dia de coleta e se possível coletar os resíduos com mais frequência, incentivar a comunidade a construir leiras de compostagem, para usar os resíduos orgânicos em tal processo, mostrando os benefícios do mesmo e as utilidades dos compostos orgânicos gerados.

Assim, à medida que as soluções técnicas são tomadas em conjunto com a viabilidade das tecnologias de tratamento para tais resíduos, menores serão os impactos para a saúde da população e para o meio ambiente.

\section{CONCLUSÕES/RECOMENDAÇÕES}

A falta de saneamento adequado na comunidade está afetando a qualidade ambiental do local, juntamente com a saúde da população. Assim, visando reduzir os impactos sociais, econômicos e ambientais, as autoridades públicas deveriam juntamente com os responsáveis pela ETA da comunidade realizar uma análise da qualidade da água do local, e identificar se a coloração e o odor da água afeta na saúde dos moradores levando informações para estes. Além da necessidade de realização de tratamento adequado dos efluentes gerados na comunidade. Propõe-se a construção de fossas de bananeiras por apresentar baixo custo, adequando-se a realidade da comunidade. Em relação aos resíduos sólidos, a coleta deve ser realizada com mais frequência e disponibilizar tambores com tampas para armazenarem os resíduos. Tendo em vista que o saneamento básico está ligado estritamente com a qualidade de vida em harmonia com o meio ambiente.

\section{REFERÊNCIAS BIBLIOGRÁFICAS}




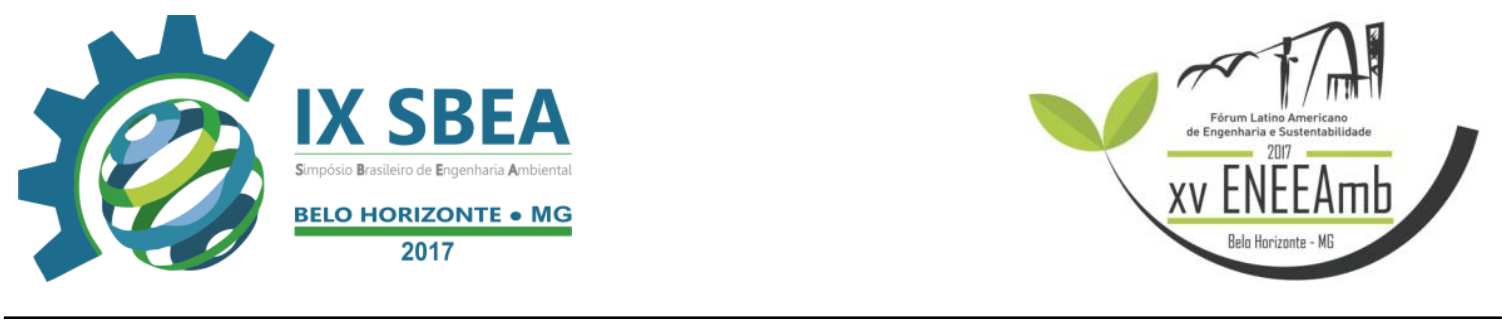

AMAVI. Manual Técnico de Orientação para Elaboração de Diagnóstico Socioambiental. Associação dos Municípios do Alto Vale do Itajaí - AMAVI, 2015.

BANDEIRA, P. "Participação, Articulação de Atores Sociais e Desenvolvimento Regional”. Texto para Discussão n. 630. Instituto de Pesquisa Econômica Aplicada. IPEA, Brasília, 1999.

BOVOLATO L.E. "Saneamento Básico e Saúde", Rev. Escritas Curso de História de Araguaína, Vol. 2: 2010.

CERQUEIRA, L "Guia do Diagnostico Participativo". FALASCO, Brasil, 2004.

COSTA, C.C.GUILHOTO J.J.M., "Saneamento Rural no Brasil: Impacto da Fossa Séptica Biodigestora”. Engenharia Sanitária e Ambiental. ISSN 14134152. 2014.

FUNDAÇÃO NACIONAL DE SAÚDE, “O desafio de universalizar o Saneamento Rural”, Dezembro de 2011 - Edição nº 10.

IBAMA. Qualidade Ambiental. Disponível em: http://www.ibama.gov.br/rqma/qualidade-ambiental. Acessado em: 11/11/16.

JÚNIOR, F. R “O saneamento básico na área rural e o papel das Associações de moradores: O caso do Bairro Jardim Vitória.”, $2013 .$.

PEREIRA, E. F., TEXEIRA, C. S., SANTOS, A. Qualidade de Vida: Abordagens, conceitos e avaliação. Revista Brasileira de Educação Física e Esporte, v. 26, n. 2, p 241-50, 2012.

RIBEIRO, J. W. ROOKE, J. M. S., "Saneamento Básico e sua relação com meio ambiente e saúde pública". Juiz de Fora-MG 2010, UFJF (Trabalho de Conclusão de Curso de Especialização). Disponível em: www.ufjf.br/analiseambiental/. Acessado em 20/04/2017.

.ROCHA, E. V. "saneamento básico no Brasil: perspectiva jurídica” 2009 revista de magistro de filosofia 2009 III, $\mathrm{n}^{\circ} .5,2010$. 